\title{
Postoperative Endophthalmitis and Toxic Anterior Segment Syndrome Prophylaxis: 2020 Update
}

\author{
Jesse D. Sengillo ${ }^{1}$, Ying Chen ${ }^{1}$, Diley Perez Garcia ${ }^{1}$, Stephen G. Schwartz ${ }^{1}$, Andrzej Grzybowski ${ }^{2,3}$, \\ Harry W. Flynn Jr ${ }^{1}$
}

${ }^{1}$ Department of Ophthalmology, Bascom Palmer Eye Institute, University of Miami Miller School of Medicine, Miami, FL, USA; ${ }^{2}$ Department of Ophthalmology, University of Warmia and Mazury, Olsztyn, Poland; ${ }^{3}$ Institute for Research in Ophthalmology, Foundation for Ophthalmology Development, Poznan, Poland

Contributions: (I) Conception and design: SG Schwartz, HW Flynn Jr; (II) Administrative support: HW Flynn Jr; (III) Provision of study materials or patients: HW Flynn Jr; (IV) Collection and assembly of data: JD Sengillo, Y Chen, D Perez Garcia; (V) Data analysis and interpretation: SG Schwartz, HW Flynn Jr, A Grzybowski; (VI) Manuscript writing: All authors; (VII) Final approval of manuscript: All authors.

Correspondence to: Stephen G. Schwartz. Department of Ophthalmology, Bascom Palmer Eye Institute, University of Miami Miller School of Medicine, 3880 Tamiami Trail North, Naples, FL 34103, USA. Email: sschwartz2@med.miami.edu.

\begin{abstract}
Improved surgical techniques have led to an increase in the number of outpatient ophthalmic procedures. In spite of decreased surgical times and overall improved outcomes, endophthalmitis remains one of the most severe complications of ophthalmic surgery. Although there are well known risk factors for postoperative endophthalmitis, some prophylaxis strategies remain controversial. A category of noninfectious postoperative inflammation, known as toxic anterior segment syndrome (TASS), is a rare but important complication of cataract surgery. While several worldwide outbreaks of TASS have occurred, it is challenging to identify an etiology in order to reduce the risk of further cases. Endophthalmitis and TASS cannot be prevented completely, but their rates may be decreased through risk reduction strategies supported by peerreviewed evidence. This review highlights the current evidence in the prevention strategies for postoperative endophthalmitis and TASS.
\end{abstract}

Keywords: Endophthalmitis; toxic anterior segment syndrome (TASS); prophylaxis

Submitted Dec 30, 2019. Accepted for publication Apr 27, 2020.

doi: 10.21037/atm-2019-rcs-02

View this article at: http://dx.doi.org/10.21037/atm-2019-rcs-02

\section{Introduction}

In the last few decades, there has been a large increase in the number of ophthalmic procedures performed worldwide. With improved surgical techniques and new technologic advances, surgical outcomes continue to improve. However, postoperative endophthalmitis and toxic anterior segment syndrome (TASS) remain important challenges. Both endophthalmitis and TASS can present as severe postoperative inflammation, and clinical characteristics may be used to differentiate between the two (Table 1). Without prompt treatment, both may lead to poor visual outcomes. Although these entities cannot be prevented completely, their rates may be decreased through risk reduction strategies supported by peer-reviewed evidence.

\section{Postoperative endophthalmitis}

\section{Background}

Acute-onset postoperative endophthalmitis is generally defined as endophthalmitis presenting within six weeks of intraocular surgery. Visual outcomes after endophthalmitis are often poor. The Endophthalmitis Vitrectomy Study (EVS) reported final visual acuity of worse than 20/100 in $36 \%$ of patients (2). In the European Society of Cataract and Refractive Surgeons (ESCRS) randomized clinical trial, $14 \%$ of patients had final visual acuity worse than or 
Table 1 Clinical characteristics of endophthalmitis and toxic anterior segment syndrome (TASS)

\begin{tabular}{lcc}
\hline Clinical characteristic & TASS & Endophthalmitis \\
\hline Timing & 12-24 hours (early) & 3-7 days (can have slight delay) \\
Pain & None to mild discomfort & Moderate to severe \\
Visual acuity & Mild decrease & Moderate to severe decrease \\
Intraocular pressure & Normal to increased & Normal \\
Corneal edema & Severe (limbus-to-limbus) & Variable extent \\
Fibrin & Mild or absent & Typically present \\
Vitreous cell & Mild or absent & Typically present \\
Hypopyon & Minimal or absent & Often present \\
\hline
\end{tabular}

Adapted from Hernandez-Bogantes et al. (1).

equal to 20/200 (3), and one review of the US Medicare population reported a similar outcome in $34 \%$ of patients with endophthalmitis (4). The reported rates of acuteonset postoperative endophthalmitis after cataract surgery vary widely, but range from about $0.02 \%$ to $0.2 \%(5,6)$. Recent evidence suggests a decline in the incidence of this complication over the last two decades, partially attributed to the refinement of surgical techniques, smaller incisions, antisepsis with povidone-iodine, and possibly the use of intracameral antibiotics by some surgeons (7-9).

\section{Risk factors}

Risk factors for endophthalmitis include preoperative, intraoperative, and postoperative factors. Preoperative factors include uncontrolled blepharitis or other ocular surface disease, diabetes mellitus, an immunocompromised state, infectious foci near the surgical site, and advanced age $(5,10-12)$. Intraoperative factors include large-incision extracapsular cataract extraction, clear cornea incision, posterior capsule rupture with or without vitreous loss, and a less experienced surgeon (3,10-13). Some authors report the non-use of intracameral antibiotics as a risk factor, but the overall benefit of intracameral antibiotics remains controversial, especially in the US (14-16). Postoperative factors include early wound leak $(17,18)$.

\section{Microbiology}

The most common causative organisms causing acuteonset postoperative endophthalmitis are gram-positive bacteria, accounting for $94.2 \%$ of culture-positive cases in the EVS. Within this group, coagulase-negative staphylococci were more common than Staphylococcus aureus and streptococci (70\% vs. $9.9 \%$ and $9 \%$, respectively) (2). Subsequent large series generally corroborate these rates $(13,19,20)$. Of the remainder, gram-negative species account for approximately $5 \%$ which includes Proteus, Haemophilus influenzae, and Pseudomonas $(2,21)$. Given the high frequency of gram-positive isolates, it is generally agreed that the main source of organisms is the ocular surface; however, Staphylococcus aureus, a highly virulent microorganism, can be found most often in the anterior nares, nasopharynx, skin, perineum, axillae, and gastrointestinal tract in asymptomatic patients (22). In the EVS, approximately $30 \%$ of patients were culture negative (21).

\section{Prophylaxis of postoperative endophthalmitis}

Although endophthalmitis cannot be prevented completely, many preoperative, intraoperative, and postoperative strategies are helpful in prophylaxis. Common practices include antisepsis with povidone-iodine and prophylactic topical antibiotics. The use of routine intracameral antibiotics has become more common in many areas of the world, although this usage remains controversial.

\section{Topical prophylaxis}

\section{Povidone-iodine}

Preoperative antisepsis with povidone-iodine significantly decreases the rate of bacterial endophthalmitis and is a worldwide accepted strategy $(5,23-26)$. Following 
conjunctival cul-de-sac irrigation with $5 \%$ povidoneiodine prior to surgery, the conjunctival flora undergoes a reported $\sim 60 \%$ reduction, especially of coagulase-negative staphylococci $(20,27)$. The additional advantages of using this agent are low cost, no known bacterial resistance, and rapid bactericidal action $(27,28)$. For skin disinfection, however, $10 \%$ povidone-iodine is generally recommended; one study reported that preoperative skin disinfection with a lower concentration of povidone-iodine was associated with an increased incidence of endophthalmitis (29). For the ocular surface, lower concentrations of povidone iodine administered as frequent applications during surgery are also shown to be effective in preventing contamination of the anterior chamber. Shimada et al. reported $0.25 \%$ povidoneiodine to be effective in this regard, in conjunction with antibiotic prophylaxis $(20,26,30)$.

Topical povidone-iodine may cause toxicity to the corneal epithelium. Ridder et al. reported that corneal staining was present for up to one day following povidone-iodine administration, associated with temporarily decreased visual acuity and contrast sensitivity (31).

When povidone-iodine cannot be used for cataract surgery (although true allergy is rare), the use of topical chlorhexidine gluconate may be considered, although this agent may be toxic to the cornea $(20,32)$.

\section{Topical antibiotics}

Although there is no conclusive evidence supporting the use of topical antibiotic prophylaxis, these agents are very widely used. For example, the 2014 American Society of Cataract and Refractive Surgery (ASCRS) survey reported that $90 \%$ of respondents used topical perioperative antibiotics and $97 \%$ of respondents used topical postoperative antibiotics (33). Many studies report a significant reduction of conjunctival flora with the use of topical antibiotics, but it is uncertain if this reduction actually decreases endophthalmitis rates (34). In the ESCRS trial, there was no significant difference in endophthalmitis rates among patients who received perioperative topical levofloxacin compared with patients who did not (3). A systematic review and meta-analysis of randomized controlled trials and observational studies performed failed to find any evidence supporting the use of postoperative topical antibiotics after ocular surgery (35). Nevertheless, these agents remain very widely used (36).

\section{Intracameral antibiotics}

Intracameral antibiotics may be used in irrigating fluids or injected as a bolus at the conclusion of surgery (37), and their use for routine prophylaxis varies widely around the world (38). In the 2014 ASCRS member survey, $47 \%$ of respondents used or planned to use intracameral antibiotics, with estimates suggesting the number would be higher if an approved, packaged commercial formulation were available in the US (38).

The ESCRS conducted a randomized clinical trial among 24 ophthalmology centers in nine different countries. Of the 16,603 patients who were recruited, 29 were diagnosed with endophthalmitis; the non-use of intracameral cefuroxime, clear corneal incisions, and silicone intraocular lenses were identified as risk factors (3). Criticisms of the ESCRS trial include the relatively high rates of endophthalmitis in patients not randomized to receive intracameral cefuroxime (approximately $0.2 \%$ ), which may have biased the results in favor of cefuroxime, as well as the use of topical levofloxacin rather than more efficacious later-generation fluoroquinolones. A recently published single-site randomized clinical trial in Brazil reported a significantly decreased rate of endophthalmitis associated with intracameral moxifloxacin ( $0.5 \%$ bolus) compared to no intracameral antibiotic (39). Again, the rate of endophthalmitis in eyes not treated with intracameral antibiotics was high $(0.38 \%)$ which may have biased the results in favor of intracameral moxifloxacin.

In addition to these two randomized clinical trials, many retrospective series have compared endophthalmitis rates in cohorts not treated with intracameral antibiotics versus cohorts treated with intracameral antibiotics. In most of these studies, the authors reported their rates after initiating routine intracameral antibiotics, and compared these patients with the patients operated before making this change. Therefore, the non-treated cohorts generally contained patients operated earlier in time than the patients in the treated cohorts, so the decreased rates of endophthalmitis in the (later) treated cohorts could have been due to factors other than the antibiotics, such as improved surgical techniques, newer lens implants, etc. Haripriya et al., in one of the largest retrospective studies, reported a 3.5 -fold reduction in the overall rate of endophthalmitis using intracameral moxifloxacin (40), 
and one study from Northern California reported a 22 fold decline in the rate of clinical endophthalmitis (19). Similar results were reported from many other nations $(8,13,33)$. Not all series reported a benefit associated with intracameral antibiotics, however. Two studies, one from Canada and another from India, reported that intracameral antibiotics were not associated with a decreased rate of endophthalmitis (41,42). Moreover, series from Japan (6) and Singapore (personal communication, Dr. Tat Keong Chan) have reported very low rates $(\leq 0.02 \%)$ of endophthalmitis with no intracameral antibiotics (43).

Intracameral antibiotics are associated with various adverse outcomes. Inadvertent overdoses of cefuroxime have known ocular toxicity and may cause TASS (44-46). There is currently no approved, packaged formulation of intracameral antibiotics in the US, and as a result, these agents must be prepared by compounding pharmacies, with associated risks of overdose, underdose, and contamination. In Europe there is a commercially available intracameral cefuroxime (Aprokam, Thea Pharmaceuticals), which alleviates some of these concerns. However, the common use of cefuroxime in Sweden has led to an increased number of cefuroxime-resistant enterococcal cases (47). This increased rate of enterococcal infections has led to the practice, in same day bilateral surgery in Sweden, of using intracameral ampicillin plus cefuroxime (13).

Intracameral vancomycin is associated with hemorrhagic occlusive retinal vasculitis (HORV) (48), and retinal toxicity is also associated with cefuroxime at high $(49,50)$ and standard intracameral doses (51).

\section{TASS}

\section{Background}

TASS is a non-infectious postoperative inflammation that occurs most commonly after cataract surgery but also may occur following keratoplasty and posterior segment procedures (52-55). It was first described in 1980 when nine eyes with intraocular lenses containing residual polishing compound on their surface developed sterile hypopyon $(56,57)$. The incidence of TASS is difficult to estimate as it is uncommon and manifests both sporadically and in clustered outbreaks. The incidence following cataract surgery is likely around 1 in $1,000(1,58)$.

Although the pathophysiology remains elusive, TASS typically represents an inflammatory response to a noninfectious substance introduced into the eye during surgery. Culprit substances leading to major outbreaks include intraocular lens contamination with small heavy metals, balanced salt solution containing endotoxin, viscoelastic, and intracameral antibiotics (59-64), although sometimes a cause is not identified (Table 2) $(58,100,101)$.

Clinical outcomes of TASS are better with prompt diagnosis and treatment with topical corticosteroids and possibly cycloplegics. Typical presentations include blurred vision within 12-48 hours of surgery without salient complaints of pain; in general, TASS patients present sooner than do patients with endophthalmitis. "Limbusto-limbus" corneal edema is characteristic of TASS and is uncommon for endophthalmitis. Other non-specific signs of anterior segment inflammation are common in both entities, such as anterior chamber cellular reaction, fibrin, and hypopyon (102).

\section{Prophylaxis of TASS}

\section{Perioperative sterilization considerations}

Similar to endophthalmitis, TASS cannot be prevented completely but the rate may be reduced. Minute amounts of foreign substances may incite inflammation, and the large number and variety of surgical instruments used, as well as their different sterilization processes, make prevention challenging. Proper cleaning of surgical instruments and sterilization remain important for reducing rates of TASS (102).

Cutler Peck et al. retrospectively queried data from site visits and questionnaires from surgical centers that reported cases of TASS between 2007 and 2009. Several risk factors associated with TASS were identified, with inadequate flushing of the phacoemulsification and irrigation/aspiration handpieces after surgery being the most common (72). Eighty-nine percent of centers visited were found to be deficient in this practice. Strict adherence to manufacturer directions for equipment sterilization is important. In addition, handpieces should be wiped with lint-free cloth or immersed in sterile water prior to flushing (103). This reduces the risk of retained debris on an instrument entering the anterior chamber of subsequent patients (104). Another identified process associated with TASS was ultrasonic bathing, with $63 \%$ of facilities utilizing this practice (72). Employed mainly for dislodging dried debris from the surface of surgical tools, this can lead to an accumulation of heat-stable endotoxins from bacteria harbored in the bath water. It is now generally 
Table 2 Etiologies of Toxic Anterior Segment Syndrome (TASS)

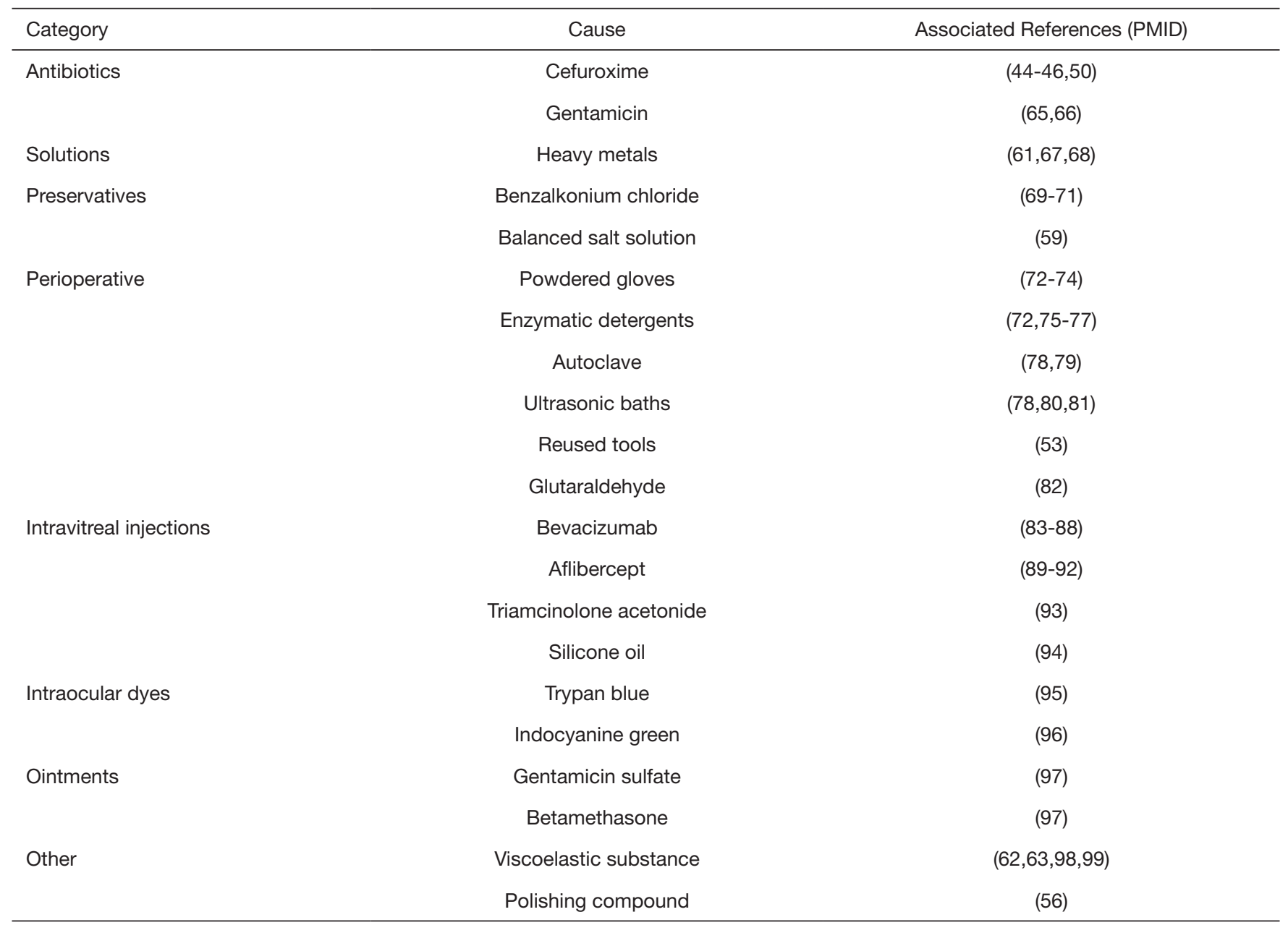

Adapted from Hernandez-Bogantes et al. (1).

recommended to avoid ultrasonic baths as proper flushing should eliminate the need for further dislodgment of surface debris $(72,103,105)$.

Impurities in steam sterilization systems are also associated with TASS. Poorly maintained autoclave generators with impurities in steam moisture were suspected to be the cause of eight TASS cases reported by Hellinger et al. (78). Investigators in this study found impurities such as sulfates, copper, zinc, nickel, and silica to be present in autoclave steam moisture in the setting of suboptimal equipment reprocessing and personnel changes. The incidence of TASS has subsequently decreased following removal of steam moisture impurities. Another outbreak was also resolved with improved autoclave maintenance, after identifying gram-negative bacteria and endotoxin in autoclave reservoirs (106).
Enzymatic detergents in the processing of surgical instruments are also associated with TASS $(72,107,108)$, with incomplete rinsing thought to leave residual detergent that can become introduced intraocularly. In vitro experiments support this as a likely cause. Endothelium of paired rabbit corneas were perfused with enzymatic detergent as compared to corneas perfused with BSS (109). A dose-related response in corneal swelling was observed, and similarly confirmed in human corneas. Thus, ASCRS and the American Society of Ophthalmic Administrators (ASOA) recommend diligent observation of instructions pertaining to proper dilution and disposal of enzymatic solutions according to the manufacturer. Extensive rinsing with copious volumes of water are used to remove all the detergent, and treating the volumes designated by the manufacturer as if they are a minimum 
needed. The final rinse should be with sterile water (105).

Bodnar et al. sought to assess how risk factors have changed for TASS over a decade, specifically before and after 2009. Their findings suggest that education and increased awareness of TASS may have improved preoperative sterilization practices (104).

\section{Materials, medications, and solutions implicated in TASS}

Numerous other agents are associated with TASS. Awareness of historical causes of TASS is helpful in reducing the risk of future outbreaks.

\section{Gloves}

Contacting an intraocular lens with a gloved hand is not a rare event (104), and talc containing surgical glove powders are known to be associated with ocular toxicity $(73,74)$. Interestingly, powder-free gloves are also associated with TASS, as gloves can retain residue from chemicals used during the extraction process in their manufacturing $(1,74)$. Avoiding direct contact between gloved hands and lens implants is advised where possible.

\section{Preservatives}

Although most surgeons have abandoned intracameral use of agents containing preservatives, inadvertent administration of these preservatives may result in TASS. Benzalkonium chloride is a frequently cited offender, and care should be taken to ensure medications instilled intracamerally do not contain this preservative (69-71). This agent not only causes dose-related inflammation to extraocular structures like the conjunctiva, it is also reported to make structural alterations to the endothelium even at exceedingly low concentrations (110). It is generally recommended to avoid the intraocular use of medications and solutions that contain benzalkonium chloride, thimerosal, eidetic acid, and sodium bisulfite (111).

\section{Intravitreal injections}

Anterior segment surgery with phacoemulsification is the most commonly implicated in TASS, but posterior surgical procedures and even intravitreal injections are frequently reported to cause a sterile inflammatory reaction. Both bevacizumab and aflibercept have been reported in past outbreaks (83-87), although it is not always clear if toxicity is inherent to the drug itself, the solution it is dissolved in (the vehicle), or the syringe used for injection (1). In one retrospective case series, the irritant was identified to be endotoxin contaminating three vials of counterfeit bevacizumab. Similarly, in a non-counterfeit lot of bevacizumab, elevated levels of endotoxin and silicone oil residues contributed to a Canada-wide TASS outbreak (85). It is important to note that bevacizumab is used offlabel for various ocular conditions, and the levels of both endotoxin and silicone oil in the lot met industry standards for intravenous use at that time. Despite the severity of intraocular inflammation in the setting anti-VEGF injections, the prognosis is often favorable (89).

\section{Aluminum and heavy metals}

One of the most widespread TASS outbreaks was from aluminum toxicity related to the use of HOYA iSert onepiece intraocular lenses, (HOYA Co Ltd, Tokyo, Japan) $(61,67)$. Six cases were also subsequently identified to cause late-onset TASS (68). A review of manufacturing practices revealed residual metallic particles on these intraocular lenses as the cause.

\section{Ointments}

Investigators at one center found an ointment containing gentamicin and betamethasone as a likely cause of eight TASS related cases, performed by the same surgeon. Mass spectrometry identified a mixed chain hydrocarbon compound on both the intraocular lens extract and within the ointment used post-operatively. The authors suggested that wound integrity and tight eye patching that was used may have contributed to the ointment gaining access into the anterior chamber.

\section{Case illustration of TASS in the setting of uncomplicated cataract surgery}

A 73-year-old man presented one day after uncomplicated cataract extraction with intraocular lens implant in the right eye. He described blurred vision without pain, instead describing mild irritation. On exam, best corrected visual acuity was $1 / 200$ with an intraocular pressure of $10 \mathrm{mmHg}$. Slit lamp examination revealed diffuse Descemet's folds and limbus to limbus corneal edema (Figure 1A). The anterior chamber exhibited a 4+ inflammatory cell reaction without hypopyon (Figure 1B). The intraocular lens appeared centered with trace fibrin on the anterior surface. There was a poor view of the posterior pole due to the anterior segment inflammation, but no frank evidence of vitritis.

Treatment with topical methylprednisolone every hour and polymyxin B sulfate/trimethoprim every four hours to 

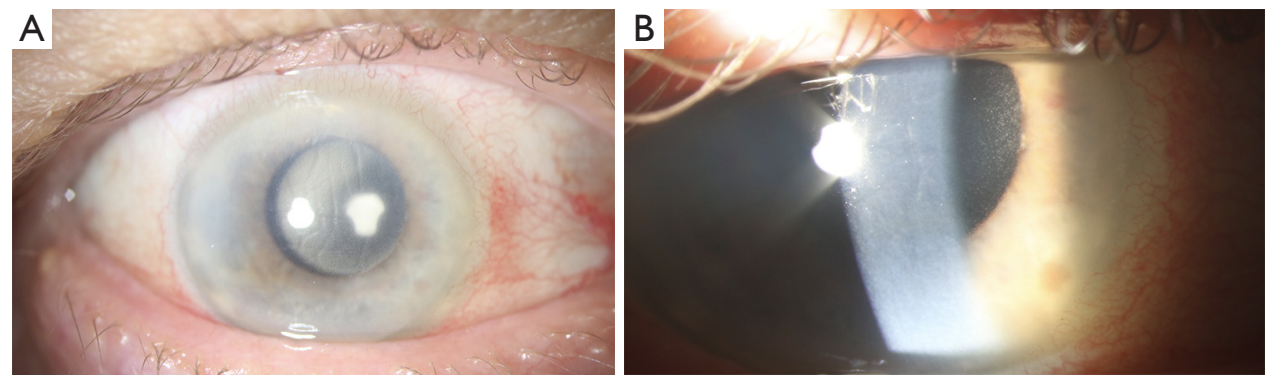

Figure 1 Slit lamp photograph of a patient with TASS. (A) Diffuse Descemet's folds and limbus to limbus corneal edema; (B) an anterior chamber 4+ inflammatory cell reaction without hypopyon.

the affected eye was initiated. By post-operative day five, visual acuity had improved to 20/60 and a slow taper of the topical steroid was initiated. At post-operative week six, visual acuity had improved to 20/30 in the affected eye.

As with all cases of post-operative inflammation following cataract surgery, endophthalmitis must be considered. In the case presented here, there was a lower suspicion for endophthalmitis as symptoms were very acute in onset-within 24 hours of surgery, and the inflammation was predominantly anterior without evidence of vitritis. An additional characteristic of TASS includes limited description of pain from the patient; blurry vision predominates. Importantly, there is commonly not a source identified for TASS, as in this case. Institutional awareness and prompt reporting of TASS should be a priority upon diagnosis.

\section{Conclusions}

Knowledge of clinical features and risk factors for postoperative endophthalmitis and TASS has increased. For both entities however, identifying the best methods of prevention remains important for improving visual outcomes after ophthalmic surgery.

\section{Acknowledgments}

Funding: This study was supported in part by an unrestricted grant from Research to Prevent Blindness (New York, New York), NIH Center Core Grant P30EY014801 (Bethesda, Maryland), and the department of Defense (DOG Grant \#W81XWH-09-1-0675) (Washington, D.C.). The sponsor or funding organization had no role in the design or conduct of this study.

\section{Footnote}

Provenance and Peer Review: This article was commissioned by the Guest Editor (Dr. Andrzej Grzybowski) for the series "Recent developments in cataract surgery" published in Annals of Translational Medicine. The article was sent for external peer review organized by the Guest Editor and the editorial office.

Conflicts of Interest: All authors have completed the ICMJE uniform disclosure form (available at http://dx.doi. org/10.21037/atm-2019-rcs-02). The series "Recent developments in cataract surgery" was commissioned by the editorial office without any funding or sponsorship. AG served as the unpaid Guest Editor of the series. SGS reports personal fees from Welch Allyn, outside the submitted work; and this study was supported in part by an unrestricted grant from Research to Prevent Blindness (New York, New York), NIH Center Core Grant P30EY014801 (Bethesda, Maryland), and the department of Defense (DOG Grant \#W81XWH-09-1-0675) (Washington, D.C.). The sponsor or funding organization had no role in the design or conduct of this study. AG reports grants from Alcon, personal fees and non-financial support from Pfizer, personal fees from Santen, grants from Zeiss, grants from Bausch \& Lomb, outside the submitted work. Dr. Flynn reports grants from Supported in part by NIH Center Core Grant P30EY014801 (Bethesda, Maryland) and Research to Prevent Blindness Unrestricted Grant to U.M during the conduct of the study. The other authors have no other conflicts of interest to declare.

Ethical Statement: The authors are accountable for all aspects of the work in ensuring that questions related 
to the accuracy or integrity of any part of the work are appropriately investigated and resolved.

Open Access Statement: This is an Open Access article distributed in accordance with the Creative Commons Attribution-NonCommercial-NoDerivs 4.0 International License (CC BY-NC-ND 4.0), which permits the noncommercial replication and distribution of the article with the strict proviso that no changes or edits are made and the original work is properly cited (including links to both the formal publication through the relevant DOI and the license). See: https://creativecommons.org/licenses/by-nc-nd/4.0/.

\section{References}

1. Hernandez-Bogantes E, Navas A, Naranjo A, et al. Toxic anterior segment syndrome: A review. Surv Ophthalmol 2019;64:463-76.

2. Endophthalmitis Vitrectomy Study Group. Results of the Endophthalmitis Vitrectomy Study. A randomized trial of immediate vitrectomy and of intravenous antibiotics for the treatment of postoperative bacterial endophthalmitis. Arch Ophthalmol 1995;113:1479-96.

3. Endophthalmitis Study Group, European Society of Cataract \& Refractive Surgeons. Prophylaxis of postoperative endophthalmitis following cataract surgery: results of the ESCRS multicenter study and identification of risk factors. J Cataract Refract Surg 2007;33:978-88.

4. Gower EW, Keay LJ, Stare DE, et al. Characteristics of endophthalmitis after cataract surgery in the United States medicare population. Ophthalmology 2015;122:1625-32.

5. Vaziri K, Schwartz SG, Kishor K, et al. Endophthalmitis: state of the art. Clin Ophthalmol 2015;9:95-108.

6. Inoue $\mathrm{T}$, Uno $\mathrm{T}$, Usui $\mathrm{N}$, et al. Incidence of endophthalmitis and the perioperative practices of cataract surgery in Japan: Japanese Prospective Multicenter Study for Postoperative Endophthalmitis after Cataract Surgery. Jpn J Ophthalmol 2018;62:24-30.

7. Keay L, Gower EW, Cassard SD, et al. Postcataract surgery endophthalmitis in the United States: analysis of the complete 2003 to 2004 Medicare database of cataract surgeries. Ophthalmology 2012;119:914-22.

8. Creuzot-Garcher C, Benzenine E, Mariet AS, et al. Incidence of Acute Postoperative Endophthalmitis after Cataract Surgery: A Nationwide Study in France from 2005 to 2014. Ophthalmology 2016;123:1414-20.

9. Nowak MS, Grzybowski A, Michalska-Malecka K, et al. Incidence and Characteristics of Endophthalmitis after
Cataract Surgery in Poland, during 2010-2015. Int J

Environ Res Public Health 2019;16:E2188.

10. Cao H, Zhang L, Li L, et al. Risk factors for acute endophthalmitis following cataract surgery: a systematic review and meta-analysis. PLoS One 2013;8:e71731.

11. Hatch WV, Cernat G, Wong D, et al. Risk factors for acute endophthalmitis after cataract surgery: a populationbased study. Ophthalmology 2009;116:425-30.

12. Garg P, Roy A, Sharma S. Endophthalmitis after cataract surgery: epidemiology, risk factors, and evidence on protection. Curr Opin Ophthalmol 2017;28:67-72.

13. Lundström M, Friling E, Montan P. Risk factors for endophthalmitis after cataract surgery: Predictors for causative organisms and visual outcomes. J Cataract Refract Surg 2015;41:2410-6.

14. Garat M, Moser CL, Martin-Baranera M, et al. Prophylactic intracameral cefazolin after cataract surgery: endophthalmitis risk reduction and safety results in a 6-year study. J Cataract Refract Surg 2009;35:637-42.

15. Romero-Aroca P, Mendez-Marin I, Salvat-Serra M, et al. Results at seven years after the use of intracamerular cefazolin as an endophthalmitis prophylaxis in cataract surgery. BMC Ophthalmol 2012;12:2.

16. Tan CS, Wong HK, Yang FP. Epidemiology of postoperative endophthalmitis in an Asian population: 11year incidence and effect of intracameral antibiotic agents. J Cataract Refract Surg 2012;38:425-30.

17. Li J, Morlet N, Ng JQ, et al. Significant nonsurgical risk factors for endophthalmitis after cataract surgery: EPSWA fourth report. Invest Ophthalmol Vis Sci 2004;45:1321-8.

18. Wallin T, Parker J, Jin Y, et al. Cohort study of 27 cases of endophthalmitis at a single institution. J Cataract Refract Surg 2005;31:735-41.

19. Shorstein NH, Winthrop KL, Herrinton LJ. Decreased postoperative endophthalmitis rate after institution of intracameral antibiotics in a Northern California eye department. J Cataract Refract Surg 2013;39:8-14.

20. Shimada H, Arai S, Nakashizuka H, et al. Reduced anterior chamber contamination by frequent surface irrigation with diluted iodine solutions during cataract surgery. Acta Ophthalmol 2017;95:e373-8.

21. Han DP, Wisniewski SR, Wilson LA, et al. Spectrum and susceptibilities of microbiologic isolates in the Endophthalmitis Vitrectomy Study. Am J Ophthalmol 1996;122:1-17.

22. Relhan N, Schwartz S, Pathengay A, et al. Endophthalmitis Caused by Methicillin-Resistant Staphylococcus aureus (MRSA). In: Das T. editor. Endophthalmitis. Singapore: 
Springer, 2018.

23. Nentwich MM, Ta CN, Kreutzer TC, et al. Incidence of postoperative endophthalmitis from 1990 to 2009 using povidone-iodine but no intracameral antibiotics at a single academic institution. J Cataract Refract Surg 2015;41:58-66.

24. Villegas VM, Schwartz SG, Grzybowski A et al. Endophthalmitis Prophylaxis: Different Practices from Around the World. In: Das T, editor. Endophthalmitis. Singapore: Springer, 2018.

25. Grzybowski A, Kanclerz P, Myers WG. The use of povidone-iodine in ophthalmology. Curr Opin Ophthalmol 2018;29:19-32.

26. Grzybowski A, Koerner JC, George MJ. Postoperative endophthalmitis after cataract surgery: a worldwide review of etiology, incidence and the most studied prophylaxis measures. Expert Rev Ophthalmol 2019;14:247-57.

27. Grzybowski A, Kuklo P, Pieczynski J, et al. A review of preoperative manoeuvres for prophylaxis of endophthalmitis in intraocular surgery: topical application of antibiotics, disinfectants, or both? Curr Opin Ophthalmol 2016;27:9-23.

28. Flynn Jr. HW, Relhan N, Schwartz SG, et al. Endophthalmitis Prophylaxis. In: Flynn HW Jr, Relhan N, Schwartz SG, et al. editors. Endophthalmitis in Clinical Practice. Cham: Springer, 2018.

29. Wu PC, Li M, Chang SJ, et al. Risk of endophthalmitis after cataract surgery using different protocols for povidone-iodine preoperative disinfection. J Ocul Pharmacol Ther 2006;22:54-61.

30. Shimada H, Arai S, Nakashizuka H, et al. Reduction of anterior chamber contamination rate after cataract surgery by intraoperative surface irrigation with $0.25 \%$ povidoneiodine. Am J Ophthalmol 2011;151:11-7.e1.

31. Ridder WH, Oquindo C, Dhamdhere K, et al. Effect of Povidone Iodine $5 \%$ on the Cornea, Vision, and Subjective Comfort. Optom Vis Sci 2017;94:732-41.

32. Montan PG, Setterquist H, Marcusson E, et al. Preoperative gentamicin eye drops and chlorhexidine solution in cataract surgery. Experimental and clinical results. Eur J Ophthalmol 2000;10:286-92.

33. Haripriya A, Baam ZR, Chang DF. Endophthalmitis Prophylaxis for Cataract Surgery. Asia Pac J Ophthalmol (Phila) 2017;6:324-9.

34. Vaziri K, Relhan N, Schwartz SG, et al. Acute-onset postoperative endophthalmitis. In: Durand M, Miller J, Young L, editors. Endophthalmitis. Cham: Springer, 2016.

35. Huang J, Wang X, Chen X, et al. Perioperative Antibiotics to Prevent Acute Endophthalmitis after Ophthalmic Surgery: A Systematic Review and Meta-Analysis. PLoS One 2016;11:e0166141.

36. Flynn HW Jr, Relhan N, Schwartz SG, et al. Antibiotic Stewardship. In: Flynn HW Jr, Relhan N, Schwartz SG, et al. Endophthalmitis in Clinical Practice. Cham: Springer, 2018.

37. Gills JP. Antibiotics in irrigating solutions. J Cataract Refract Surg 1987;13:344.

38. Chang DF, Braga-Mele R, Henderson BA, et al. Antibiotic prophylaxis of postoperative endophthalmitis after cataract surgery: Results of the 2014 ASCRS member survey. J Cataract Refract Surg 2015;41:1300-5.

39. Melega MV, Alves M, Cavalcanti Lira RP, et al. Safety and efficacy of intracameral moxifloxacin for prevention of post-cataract endophthalmitis: Randomized controlled clinical trial. J Cataract Refract Surg 2019;45:343-50.

40. Haripriya A, Chang DF, Ravindran RD. Endophthalmitis Reduction with Intracameral Moxifloxacin Prophylaxis: Analysis of 600000 Surgeries. Ophthalmology 2017;124:768-75.

41. Rudnisky CJ, Wan D, Weis E. Antibiotic choice for the prophylaxis of post-cataract extraction endophthalmitis. Ophthalmology 2014;121:835-41.

42. Sharma S, Sahu SK, Dhillon V, et al. Reevaluating intracameral cefuroxime as a prophylaxis against endophthalmitis after cataract surgery in India. J Cataract Refract Surg 2015;41:393-9.

43. Grzybowski A, Schwartz SG, Matsuura K, et al. Endophthalmitis Prophylaxis in Cataract Surgery: Overview of Current Practice Patterns Around the World. Curr Pharm Des 2017;23:565-73.

44. Filip M, Dragne C, Filip A, et al. Toxic anterior segment syndrome. Oftalmologia 2006;50:27-9.

45. Çakır B, Celik E, Aksoy NÖ, et al. Toxic anterior segment syndrome after uncomplicated cataract surgery possibly associated with intracamaral use of cefuroxime. Clin Ophthalmol 2015;9:493-7.

46. Gardner S, Barry P, Cordoves L. Toxic anterior segment syndrome and intracameral injection of cefuroxime axetil. Clin Ophthalmol 2015;9:1865-7.

47. Friling E, Montan P. Bacteriology and cefuroxime resistance in endophthalmitis following cataract surgery before and after the introduction of prophylactic intracameral cefuroxime: a retrospective single-centre study. J Hosp Infect 2019;101:88-92.

48. Miyake H, Miyazaki D, Shimizu Y, et al. Toxicities of and inflammatory responses to moxifloxacin, cefuroxime, and 
vancomycin on retinal vascular cells. Sci Rep 2019;9:9745.

49. Çiftçi S, Çiftçi L, Da U. Hemorrhagic retinal infarction due to inadvertent overdose of cefuroxime in cases of complicated cataract surgery: retrospective case series. Am J Ophthalmol 2014;157:421-5.e2.

50. Kamal-Salah R, Osoba O, Doyle E. Ocular Toxicity after Inadvertent Intracameral Injection of High Dose of Cefuroxime during Cataract Surgery: A Case Series. Retin Cases Brief Rep 2019;13:269-72.

51. Faure C, Perreira D, Audo I. Retinal toxicity after intracameral use of a standard dose of cefuroxime during cataract surgery. Doc Ophthalmol 2015;130:57-63.

52. Maier P, Birnbaum F, Bohringer D, et al. Toxic anterior segment syndrome following penetrating keratoplasty. Arch Ophthalmol 2008;126:1677-81.

53. Sevimli N, Karadag R, Cakici O, et al. Toxic anterior segment syndrome following deep anterior lamellar keratoplasty. Arq Bras Oftalmol 2016;79:330-2.

54. Park CY, Lee JK, Chuck RS. Toxic anterior segment syndrome-an updated review. BMC Ophthalmol 2018;18:276.

55. Patel SB, Reddy NK, He YG. Toxic Posterior Segment Syndrome after Dropless Cataract Surgery with Compounded Triamcinolone-Moxifloxacin. Retina 2020;40:446-55.

56. Meltzer DW. Sterile hypopyon following intraocular lens surgery. Arch Ophthalmol 1980;98:100-4.

57. Monson MC, Mamalis N, Olson RJ. Toxic anterior segment inflammation following cataract surgery. J Cataract Refract Surg 1992;18:184-9.

58. Sengupta S, Chang DF, Gandhi R, et al. Incidence and long-term outcomes of toxic anterior segment syndrome at Aravind Eye Hospital. J Cataract Refract Surg 2011;37:1673-8.

59. Kutty PK, Forster TS, Wood-Koob C, et al. Multistate outbreak of toxic anterior segment syndrome, 2005. J Cataract Refract Surg 2008;34:585-90.

60. Buzard K, Zhang JR, Thumann G, et al. Two cases of toxic anterior segment syndrome from generic trypan blue. J Cataract Refract Surg 2010;36:2195-9.

61. Suzuki T, Ohashi Y, Oshika T, et al. Outbreak of lateonset toxic anterior segment syndrome after implantation of one-piece intraocular lenses. Am J Ophthalmol 2015;159:934-9.e2.

62. Althomali TA. Viscoelastic substance in prefilled syringe as an etiology of Toxic Anterior Segment Syndrome. Cutan Ocul Toxicol 2016;35:237-41.
63. Altıntaş AK, Ciritoğlu MY, BeyazyıldıZ Ö, et al. Toxic Anterior Segment Syndrome Outbreak after Cataract Surgery Triggered by Viscoelastic Substance. Middle East Afr J Ophthalmol 2017;24:43-7.

64. Oshika T, Eguchi S, Goto H, et al. Outbreak of SubacuteOnset Toxic Anterior Segment Syndrome Associated with Single-Piece Acrylic Intraocular Lenses. Ophthalmology 2017;124:519-23.

65. Litwin AS, Pimenides D. Toxic anterior segment syndrome after cataract surgery secondary to subconjunctival gentamicin. J Cataract Refract Surg 2012;38:2196-7.

66. Koban Y, Genc S, Bilgin G, et al. Toxic Anterior Segment Syndrome following Phacoemulsification Secondary to Overdose of Intracameral Gentamicin. Case Rep Med 2014;2014:143564.

67. Kumaran N, Larkin G, Hollick EJ. Sterile postoperative endophthalmitis following HOYA IOL insertion. Eye (Lond) 2014;28:1382.

68. Miyake G, Ota I, Miyake K, et al. Late-onset toxic anterior segment syndrome. J Cataract Refract Surg 2015;41:666-9.

69. Liu H, Routley I, Teichmann KD. Toxic endothelial cell destruction from intraocular benzalkonium chloride. J Cataract Refract Surg 2001;27:1746-50.

70. Eleftheriadis H, Cheong M, Sandeman S, et al. Corneal toxicity secondary to inadvertent use of benzalkonium chloride preserved viscoelastic material in cataract surgery. Br J Ophthalmol 2002;86:299-305.

71. Bielory BP, Shariff A, Hussain RM, et al. Toxic Anterior Segment Syndrome: Inadvertent Administration of Intracameral Lidocaine $1 \%$ and Phenylephrine $2.5 \%$ Preserved With 10\% Benzalkonium Chloride During Cataract Surgery. Cornea 2017;36:621-4.

72. Cutler Peck CM, Brubaker J, Clouser S, et al. Toxic anterior segment syndrome: common causes. J Cataract Refract Surg 2010;36:1073-80.

73. Bene C, Kranias G. Possible intraocular lens contamination by surgical glove powder. Ophthalmic Surg 1986;17:290-1.

74. Cox MJ, Woods JA, Newman S, et al. Toxic effects of surgical glove powders on the eye. J Long Term Eff Med Implants 1996;6:219-26.

75. Leder HA, Goodkin M, Buchen SY, et al. An investigation of enzymatic detergents as a potential cause of toxic anterior segment syndrome. Ophthalmology 2012;119:e30-5.

76. Tamashiro NS, Souza RQ, Goncalves CR, et al. 
Cytotoxicity of cannulas for ophthalmic surgery after cleaning and sterilization: evaluation of the use of enzymatic detergent to remove residual ophthalmic viscosurgical device material. J Cataract Refract Surg 2013;39:937-41.

77. Mamalis N, Edelhauser HF. Enzymatic detergents and toxic anterior segment syndrome. Ophthalmology 2013;120:651-2.

78. Hellinger WC, Hasan SA, Bacalis LP, et al. Outbreak of toxic anterior segment syndrome following cataract surgery associated with impurities in autoclave steam moisture. Infect Control Hosp Epidemiol 2006;27:294-8.

79. Sorenson AL, Sorenson RL, Evans DJ. Toxic anterior segment syndrome caused by autoclave reservoir wall biofilms and their residual toxins. J Cataract Refract Surg 2016;42:1602-14.

80. Richburg FA, Reidy JJ, Apple DJ, et al. Sterile hypopyon secondary to ultrasonic cleaning solution. J Cataract Refract Surg 1986;12:248-51.

81. Kreisler KR, Martin SS, Young CW, et al. Postoperative inflammation following cataract extraction caused by bacterial contamination of the cleaning bath detergent. J Cataract Refract Surg 1992;18:106-10.

82. Unal M, Yucel I, Akar Y, et al. Outbreak of toxic anterior segment syndrome associated with glutaraldehyde after cataract surgery. J Cataract Refract Surg 2006;32:1696-701.

83. Wickremasinghe SS, Michalova K, Gilhotra J, et al. Acute intraocular inflammation after intravitreous injections of bevacizumab for treatment of neovascular age-related macular degeneration. Ophthalmology 2008;115:1911-5.

84. Sato T, Emi K, Ikeda T, et al. Severe intraocular inflammation after intravitreal injection of bevacizumab. Ophthalmology 2010;117:512-6

85. Fielden M, Nelson B, Kherani A. Acute intraocular inflammation following intravitreal injection of bevacizumab--a large cluster of cases. Acta Ophthalmol 2011;89:e664-5.

86. Wang F, Yu S, Liu K, et al. Acute intraocular inflammation caused by endotoxin after intravitreal injection of counterfeit bevacizumab in Shanghai, China. Ophthalmology 2013;120:355-61.

87. Orozco-Hernández A, Ortega-Larrocea X, SánchezBermúdez G, et al. Acute sterile endophthalmitis following intravitreal bevacizumab: case series. Clin Ophthalmol 2014;8:1793-9.

88. Kay CN, Tarantola RM, Gehrs KM, et al. Uveitis following intravitreal bevacizumab: a non-infectious cluster. Ophthalmic Surg Lasers Imaging 2011;42:292-6.

89. Hahn P, Chung MM, Flynn HW Jr, et al. Postmarketing analysis of aflibercept-related sterile intraocular inflammation. JAMA Ophthalmol 2015;133:421-6.

90. Hahn P, Kim JE, Stinnett S, et al. Aflibercept-related sterile inflammation. Ophthalmology 2013;120:1100-101. e1-5

91. Goldberg RA, Shah CP, Wiegand TW, et al. Noninfectious inflammation after intravitreal injection of aflibercept: clinical characteristics and visual outcomes. Am J Ophthalmol 2014;158:733-7.e1.

92. Greenberg JP, Belin P, Butler J, et al. Aflibercept-Related Sterile Intraocular Inflammation Outcomes. Ophthalmol Retina 2019;3:753-9.

93. Kim M, Yu SY, Kwak HW. Sterile endophthalmitis following intravitreal triamcinolone acetonide in July 2010. Indian J Ophthalmol 2015;63:467-8.

94. Moisseiev E, Barak A. Toxic anterior segment syndrome outbreak after vitrectomy and silicone oil injection. Eur J Ophthalmol 2012;22:803-7.

95. Matsou A, Tzamalis A, Chalvatzis N, et al. Generic trypan blue as possible cause of a cluster of toxic anterior segment syndrome cases after uneventful cataract surgery. J Cataract Refract Surg 2017;43:848-52.

96. Tandogan T, Khoramnia R, Uwe Auffarth G, et al. Impact of indocyanine green concentration, exposure time, and degree of dissolution in creating toxic anterior segment syndrome: evaluation in a rabbit model. J Ophthalmol 2016;2016:3827050.

97. Werner L, Sher JH, Taylor JR, et al. Toxic anterior segment syndrome and possible association with ointment in the anterior chamber following cataract surgery. J Cataract Refract Surg 2006;32:227-35.

98. Kim JH. Intraocular inflammation of denatured viscoelastic substance in cases of cataract extraction and lens implantation. J Cataract Refract Surg 1987;13:537-42.

99. Kremer I, Levinger E, Levinger S. Toxic anterior segment syndrome following iris-supported phakic IOL implantation with viscoelastic Multivisc BD. Eur J Ophthalmol 2010;20:451-3.

100. Choi JS, Shyn KH. Development of toxic anterior segment syndrome immediately after uneventful phaco surgery. Korean J Ophthalmol 2008;22:220-7.

101. Nizamani NB, Bhutto IA, Talpur KI. Cluster of UrretsZavalia syndrome: a sequel of toxic anterior segment syndrome. Br J Ophthalmol 2013;97:976-9. 
102. Shouchane-Blum K, Dotan A, Bahar I. The evolution of toxic anterior segment syndrome. Curr Opin Ophthalmol 2019;30:50-5.

103. American Society of Cataract and Refractive Surgery, American Society of Ophthalmic Registered Nurses. Recommended practices for cleaning and sterilizing intraocular surgical instruments. Insight 2007;32:22-8.

104. Bodnar Z, Clouser S, Mamalis N. Toxic anterior segment syndrome: Update on the most common causes. J Cataract Refract Surg 2012;38:1902-10.

105. Hellinger WC, Bacalis LP, Edelhauser HF, et al. Recommended practices for cleaning and sterilizing intraocular surgical instruments. J Cataract Refract Surg 2007;33:1095-100.

106. Holland S, Morck M. Autoclave contamination and TASS.
Cataract \& Refractive Surgery Today 2006;July:58-60.

107. Carter LM, Duncan G, Rennie GK. Effects of detergents on the ionic balance and permeability of isolated bovine cornea. Exp Eye Res 1973;17:409-16.

108. Breebaart AC, Nuyts RM, Pels E, et al. Toxic endothelial cell destruction of the cornea after routine extracapsular cataract surgery. Arch Ophthalmol 1990;108:1121-5.

109.Parikh C, Sippy BD, Martin DF, et al. Effects of enzymatic sterilization detergents on the corneal endothelium. Arch Ophthalmol 2002;120:165-72.

110.Parikh CH, Edelhauser HF. Ocular surgical pharmacology: corneal endothelial safety and toxicity. Curr Opin Ophthalmol 2003;14:178-85.

111.Johnston J. Toxic anterior segment syndrome--more than sterility meets the eye. AORN J 2006;84:969-84.

Cite this article as: Sengillo JD, Chen Y, Perez Garcia D, Schwartz SG, Grzybowski A, Flynn HW Jr. Postoperative Endophthalmitis and Toxic Anterior Segment Syndrome Prophylaxis: 2020 Update. Ann Transl Med 2020;8(22):1548. doi: 10.21037/atm-2019-rcs-02 